\title{
A concepção de politecnia em Moçambique: contradições de um discurso socialista (1983-1992)*
}

\author{
António Cipriano Parafino Gonçalves \\ Universidade Federal de Minas Gerais
}

Correspondência:

António Cipriano P. Gonçalves

Al. das Latânias, 1000, ap 301

31270-800 - Belo Horizonte, MG

e-mail: ciprix@yahoo.com

"Elaborado com base na dissertação de mestrado sob a orientação da Profa. Dra. Maria de Lourdes Rocha de Lima e coorientação da Profa. Dra. Rosemary Dore Soares, a quem agradeço pelas valiosas contribuições na elaboração da dissertação e também à CAPES pela concessão da bolsa de estudos de mestrado no âmbito do Programa de Estudante de Convénio (PEC-PG).

\section{Resumo}

0 trabalho analisa a fundamentação do conceito de politecnia na educação moçambicana, de acordo com o projeto político proposto pela Frente de Libertação de Moçambique (Frelimo), que preconizava a instauração de uma sociedade socialista nesse país. Definida nos documentos oficiais como tradução do princípio pedagógico de ligação entre a teoria e a prática, entre a escola e o trabalho, a politecnia deveria permear todo o processo de formação escolar e visava propiciar aos alunos bases para compreender a realidade, assimilar o conhecimento científico e transformar a natureza e a sociedade. Metodologicamente, foi realizada uma pesquisa teórica, revisando a bibliografia sobre o surgimento do conceito de politecnia, o entendimento deste em Marx, Lênin e no movimento operário russo. Também foram consultados documentos oficiais, artigos, livros e resultados de pesquisas sobre a educação socialista moçambicana que focassem o propósito da pesquisa. Empiricamente, realizaram-se entrevistas com intelectuais que estiveram envolvidos com a educação moçambicana no período recortado (1983-1992), na cidade de Maputo, entre janeiro e março de 2005. Da análise de dados e do conteúdo das entrevistas, conclui-se, primeiro, que existe uma diferença na fundamentação da concepção de educação politécnica na proposta pedagógica de Moçambique em relação às propostas sejam de Marx e Lênin. Segundo, que o entendimento do conceito de politecnia em Moçambique foi limitado e que o discurso socialista que acompanhou a educação moçambicana foi contraditório.

\section{Palavras-chave}

Moçambique - Frelimo - Estado-nação moderno - Sistema Nacional de Educação - Concepção de educação politécnica. 


\title{
The idea of polytechnicalism in Mozambique: contradictions of a socialist discourse (1983-1992)*
}

\author{
António Cipriano Parafino Gonçalves \\ Universidade Federal de Minas Gerais
}

Contact:

António Cipriano P. Gonçalves Al. das Latânias, 1000, ap 301 31270-800 - Belo Horizonte, MG e-mail: ciprix@yahoo.com

\begin{abstract}
The work analyzes the grounding of the concept of polytechnicalism in Mozambican education, according to the political project proposed by the Mozambican Liberation Front (FRELIMO), which defended the establishment of a socialist nation in that country. Defined in the official documents as a translation of the pedagogical principle of the connection between theory and practice, between school and work, polytechnicalism should permeate the whole process of schooling, and aimed at giving students the basis to understand reality, assimilating scientific knowledge, and transforming nature and society. In terms of methodology, the work comprised a theoretical survey of the literature on the emergence of the concept of polytechnicalism, and the understanding of this concept in Marx and Lenin, as well as in the Russian workers movement. Official documents, articles, books, and the results of related research on the Mozambican "socialist" education were also investigated. In its empirical part, the study included interviews with intellectuals that were involved with Mozambican education during the period in question (1983-1992) in the city of Maputo; these interviews were conducted between January and March 2005. From the analysis of the data collected and interviews carried out, the study allowed the conclusion that, firstly, there is a difference between the grounding of the conception of polytechnic education as it appears in the Mozambican pedagogical proposal, and those of Marx or Lenin. Secondly, that the understanding of the concept of polytechnicalism in Mozambique was limited, and that the socialist discourse that attended Mozambican education was contradictory.
\end{abstract}

\section{Keywords}

Mozambique - Frelimo - Modern nation-state - National Education System - Concept of Polytechnic education.

\footnotetext{
This article is based on the Master Dissertation prepared under the supervision of Professor Maria de Lourdes Rocha de Lima and cosupervision of Professor Rosemary Dore Soares, to which the author wishes the express his gratitude. The Master studies were sponsored by CAPES through a scholarship offered within the Exchange Student Program (PEC-PG).
} 
0 trabalho, síntese da dissertação de mestrado defendida em novembro de 2005, analisa a fundamentação do conceito de politecnia presente no projeto socialista para a educação moçambicana, apresentado pela Frente de Libertação de Moçambique (Frelimo)', entre 1983 e 1992, em vista a edificar o socialismo após a independência do país, ocorrida em 1975. Definido, naquele projeto educacional, como "tradução do princípio pedagógico de ligação entre a teoria e a prática, entre a escola e o trabalho produtivo no processo educativo" (Moçambique, 1985, p. 112), o conceito de politecnia deveria permear todo o processo de formação escolar e visava propiciar aos alunos "bases para compreender a realidade, assimilar o conhecimento científico e transformar a natureza e a sociedade" (Moçambique, 1985, p. 21).

Em torno do conceito de politecnia, entretanto, há uma grande polêmica e existem diferentes interpretações sobre ele. Somente para exemplificar, no socialismo real, o conceito se consolidou como expressão da síntese do pensamento marxista sobre a educação escolar. No entanto, em Marx, a politecnia ou educação tecnológica constitui uma das três dimensões da sua concepção educacional, que abrange também a educação intelectual (da mente) e a ginástica (Marx; Engels, 2004).

Durante a Revolução Soviética, o conceito foi adotado por Lênin e Krupskaia, sem desprezar a dimensão da educação geral, isto é, o conceito de politecnia "não sintetizava todas as possibilidades de ligação entre o trabalho e o estudo" (Dore Soares, 2000, p. 345-346). Após a ascensão de Stalin, o conceito de politecnia foi se afirmando "para designar a educação relacionada ao trabalho industrial, desvinculada da formação geral” (p. 350).

Não obstante esses exemplos em torno da complexidade do conceito, foi o termo politecnia que acabou ficando conhecido no socialismo real como sinônimo de uma concepção socialista de vinculação entre trabalho e ensino.

De que modo o conceito de politecnia chegou a Moçambique?
Quando da independência do país, técnicos estrangeiros oriundos dos ex-países socialistas chegaram a Moçambique em apoio à revolução, no âmbito do internacionalismo proletário. Os técnicos em referência, segundo Brito (1995), ocuparam funções de "especialistas ou de conselheiros nos gabinetes de estudos, nos departamentos de planificação dos ministérios” (p. 11), e alguns se envolveram com o processo da organização da educação escolar moçambicana ${ }^{2}$. Possivelmente, teria sido a partir desse envolvimento que esses técnicos influenciaram a adoção da perspectiva educacional que vigorava em seus respectivos países.

Entretanto, a explicação oficial relativa à adoção da politecnia em Moçambique encontra-se nos documentos do ex-Ministério da Educação e Cultura do país (MEC) ${ }^{3}$. Ali é afirmado que "foi do combate pela libertação da terra e dos homens", nas Zonas Libertadas, que foram forjados "os princípios que orientam a nossa sociedade e educação" (MEC, 1980, p. 2) ${ }^{4}$. Naquelas zonas, refere o documento oficial, o trabalho manual e a produção já "faziam parte da educação, garantindo a unidade entre estudo e o trabalho produtivo, entre o trabalho intelectual e o manual" (MEC, 1980, 11, p. 1).

Essa explicação oficial sugere não ter havido influências externas na proposição e adoção do conceito na educação escolar moçambicana. Contudo, o que os organizadores da educação moçambicana entendiam por princípio pedagógico de ligação entre a teoria e a prática, entre a escola e o trabalho, como ex-

1. A Frelimo, de acordo com os documentos oficiais, nasceu da unificação de três movimentos nacionalistas moçambicanos em junho de 1962, na capital da Tanzânia - Dar-Es-Salam. São eles, a União Nacional Africana de Moçambique (MANU) do norte do país; a União Nacional Democrática de Moçambique (UDENAMO), centro; e a União Nacional Africana de Moçambique Independente (UNAMI), fundada na Província de Tete (centro do país).

2. Na Educação, houve uma presença significativa dos técnicos provindos da antiga República Democrática Alemã. Informação dada por Luís Filipe em 15 de janeiro de 2005 em Maputo.

3. 0 documento em referência, depositado na Biblioteca do Centro de Estudos Africanos da Universidade Eduardo Mondlane, em Maputo, pasta 67.9 6/KL, é a versão não divulgada das Linhas Gerais do Sistema Nacional de Educação. 4. As Zonas Libertadas, situadas no interior das províncias de Niassa e Cabo Delgado, no norte de Moçambique, são as áreas que passaram para o controle da Frelimo no decurso da luta armada 
pressão da politecnia? A que resultados chegou a educação moçambicana orientada pelo conceito de politecnia?

Essas foram as principais questões das quais partiu o estudo. Da análise sobre a fundamentação do conceito de politecnia, é sustentada a tese de que o entendimento desse conceito em Moçambique foi limitado. Além da limitação quanto ao entendimento do conceito, ainda em nível educacional, o discurso que acompanhou a fundamentação da politecnia foi contraditório com relação aos propósitos socialistas dos dirigentes moçambicanos.

Para se chegar a essa conclusão, foi realizada uma pesquisa teórica, revisando a bibliografia geral sobre o conceito de politecnia. Também foram consultados documentos oficiais, artigos, livros e resultados de pesquisa sobre a educação socialista moçambicana que focassem o propósito de pesquisa ${ }^{5}$. Empiricamente, realizaram-se entrevistas com alguns intelectuais ${ }^{6}$ que estiveram envolvidos com a educação moçambicana no período recortado (19831992), na cidade de Maputo-Moçambique, entre janeiro e março de 2005.

São expostos, a seguir, os resultados de investigação, apresentando, primeiro, a emergência da politecnia na educação moçambicana, situando o contexto histórico em que surge essa proposta. Depois é discutida a emergência da politecnia na história da Educação, a compreensão que Marx e Lênin tiveram desta e o rumo que ela seguiu no movimento operário russo. Por fim, é analisada a fundamentação do conceito de politecnia na educação moçambicana, à luz do discurso socialista dos dirigentes moçambicanos.

\section{A emergência do conceito de politecnia na educação moçambicana}

Segundo se referiu, o conceito de politecnia, na educação escolar moçambicana, surgiu da experiência educacional havida nas Zonas Libertadas, no decurso da Luta de Libertação de Moçambique do domínio português. Conforme Munslow
(1983), de objetivos independentistas e nacionalistas, a luta armada, dirigida pela Frelimo, passou a ter um caráter revolucionário. A Frente pretendia operar uma radical transformação das relações sociais em Moçambique para construir uma nova sociedade, livre de exploração do homem pelo homem, em que "as condições materiais de vida do povo melhorem continuamente e [...] suas necessidades sociais sejam satisfeitas" (Frelimo, 1983a, p. 31).

Após a independência, a Frelimo buscou efetivar o projeto de Estado e de sociedade nascido durante a luta de libertação, estendendo a todo o país o processo de destruição da velha sociedade.

Foi nesse contexto que o MEC, seguindo as orientações do 111 Congresso da Frelimo, elaborou uma proposta educacional para dar início à reorganização da educação escolar moçambicana. Chamada de Linhas Gerais do Sistema Nacional de Educação, a proposta foi apresentada pelo MEC à ex-Assembléia Popular ${ }^{7}$ em 1981, tendo sido aprovada sob forma de lei com denominação de Sistema Nacional de Educação (SNE) - (Lei 4/83, de 23 de Março de 1983).

O objetivo central atribuído ao SNE era o de formar o Homem Novo Revolucionário: "um homem livre do obscurantismo, da superstição e da mentalidade burguesa e colonial, um homem que assume os valores da sociedade socialista” (Moçambique, 1985, p. 113). Eram os fundamentos da nova educação, além da experiência educacional havida nas Zonas Libertadas, a Constituição da República (1975 e 1978), o Programa do Partido Frelimo "e os princípios universais do marxismo-leninismo, particularmente os que se referem à pedagogia socialista" (Moçambique, 1985, p. 17).

5. Fazem parte dos documentos oficiais os relatórios técnicos, os discursos dos dirigentes moçambicanos, a legislação educacional e toda a documentação produzida no Ministério de Educação e Cultura de Moçambique.

6. No sentido gramsciano do termo (Gramsci, 2004).

7. No âmbito da mudança, de orientação política e da reforma do Estado moçambicano, a Assembléia Popular passou ser designada de Assembléia da República.

8. A lei de nacionalização dos serviços de Saúde, Educação e Habitação foi promulgada em 24 de Julho de 1975. 
Ainda no contexto da reorganização educacional, o Estado decretou a nacionalização da educação escolar, justificando que pretendia democratizar o acesso a ela, "sem discriminação de origem econômica e racial" (Moçambique, 1985, p. 11), em função de a educação colonial ter imposto "a existência de dois sistemas de ensino perfeitamente distintos e discriminados"

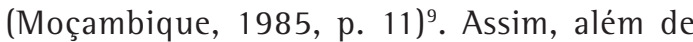
garantir a igualdade socioeducacional, a nacionalização da educação também era fundamental para a formação do Homem Novo Revolucionário, ele que era a garantia da irreversibilidade do processo revolucionário em Moçambique (Machel, 1978a).

Segundo referiu Samora Machel (1978a), é na educação escolar "onde se forma o homem $^{10}$. 0 segredo está aí [...] um homem novo? Uma sociedade nova? Não, é na escola, na educação, onde está o germe, o segredo" (p. 35). Samora Machel enfatizou que formar o Homem Novo era formar uma nova mentalidade porque, para ele, não era somente ensinando "a falar e escrever bem que conseguiriamos formar um outro homem" (p. 35). Com uma nova mentalidade, defendeu Machel, vão germinar novas idéias, que lutam "permanentemente contra as ideias velhas, contra os hábitos velhos [...] surge o combate para dinamizar e revigorar o novo. Novo com conteúdo revolucionário (p.2).

No entanto, para os dirigentes e intelectuais moçambicanos, a formação do Homem Novo era um problema cultural. No entendimento de Sérgio Vieira" (1977), a difusão, a propagação, a promoção e o desenvolvimento de nova cultura são as mais importantes dimensões na criação do Homem Novo. Por isso que Machel (1979b) defendeu a centralidade da cultura para a revolução.

A crítica dos dirigentes e intelectuais moçambicanos, entretanto, era direcionada contra a educação tradicional e a colonial. Eles sustentavam que, nesse tipo de educação, a superstição tomou conta da ciência, integrado "a juventude nas velhas ideias das gerações passadas", e levou à "destituição da iniciativa intelectual e à paralisia da sociedade”. Então, contra a destituição da iniciativa intelectual e a paralisia social, a educação revolucionária deveria

[...] eliminar a superstição, criar uma nova sociedade, forte, sã, próspera, livre da exploração, e ensinar às crianças a pensarem cientificamente. (CEA, s/d, p. 3-4)

0 ensino colonial, para os intelectuais e dirigentes moçambicanos, era elitista e por isso "desprezou o trabalho manual e separou a teoria da prática" (Moçambique, 1985, p. 12). Para superar esse elitismo, era necessário que a nova educação se orientasse pelo princípio pedagógico de ligação entre a teoria e a prática, entre a escola e o trabalho produtivo, adquirindo, desse modo, um caráter politécnico. Esse método educativo, segundo os documentos oficiais, começou nas Zonas Libertadas.

Entretanto, em relação à experiência educacional dessas zonas, o discurso oficial limita-se a fazer alusão a estas como referência para a nova educação, sem nunca apresentar dados qualitativos ou quantitativos a respeito do número de escolas ali existentes. Os documentos pesquisados apenas argumentam que foi naquelas Zonas onde começou o combate pela formação de nova mentalidade, livre do obscurantismo, da superstição e do dogmatismo transmitidos pela educação tradicional; o combate à mentalidade colonial e burguesa transmitida pela educação colonial (CEA, s/d; Frelimo, 1977d).

Em relação ao princípio de politecnia ali nascido, uma única referência encontrada é o relato do professor Roque Vicente, diretor da Escola Piloto de Tete ${ }^{12}$, fundada em 1970. Segundo o professor, o dia começava com o trabalho manual (não explicitado). Pela tarde, após o almoço, o trabalho manual era efetua-

\footnotetext{
9. Samora Machel foi o segundo presidente da Frelimo, após a morte de Eduardo Mondlane (1969). Após a independência, tornou-se no primeiro presidente de Moçambique. Morreu em acidente de aviação em 19 de outubro de 1986.

10. Sérgio Vieira foi membro do Bureau Político da Frelimo e Ministro da Segurança até a morte de Samora Machel.

11. Província do centro de Moçambique.

12. 0 trabalho, nesse trecho, é usado no sentido de profissão ou ofício.
} 
do na terra ou "na manutenção dos territórios e instalações” (CEA, s/d, p. 7).

Para se garantir o princípio de ligação entre a teoria e a prática, com base no trabalho, prossegue o professor Roque Vicente, "os alunos faziam a patrulha, participavam da agricultura, cada um tomando parte no cultivo dos campos da escola”. Os estudantes também se dispunham para auxiliarem aos aldeãos "em várias tarefas, tais como a agricultura, a construção de casas e a limpeza”. A população, por sua vez, agradecia aos alunos "ajudando a escola na alimentação, emprestando machados, enxadas e outros utensílios”. Além disso, os aldeãos ensinavam aos estudantes "coisas como fazer esteiras e outras manufaturas". Os estudantes, por sua vez, "ensinavam aos aldeãos a ler e a escrever” (CEA, s/d, p. 9-10). Desse modo, estava garantido o ensino politécnico, ligando a teoria e a prática, a escola e a comunidade, a escola e o trabalho produtivo.

Essa experiência educacional das Zonas Libertadas tinha mostrado para a Frelimo a exigência de formar o Homem Novo, libertando a sua "iniciativa criadora, unindo cada vez mais a teoria e a prática, formando também uma mentalidade científica, materialista e dialéctica" (MEC, 1980, p. 3).

Por isso, quando da organização do SNE, foi definido como objetivo da área politécnica, “a transmissão das bases científico-técnicas da produção, o desenvolvimento de capacidade de trabalho produtivo e a ligação constante dos conhecimentos adquiridos à prática da vida social e à produção" (Moçambique, 1985, p. 20). 0 ensino das bases científico-técnicas é justificado com base no argumento de que "a ciência e a técnica devem ser apropriadas pelas massas populares" (MEC, 1980, p. 2), garantindo a "igualdade de oportunidades que tem qualquer cidadão de acesso a todos os níveis de ensino e educação" (MEC, 1980, p. 2).

Seria, portanto, por meio da politecnia, segundo a experiência educacional havida nas Zonas Libertadas, que se poderia formar o Homem Novo Revolucionário, "que transforma a natureza e a sociedade" (Moçambique, 1985, p. 21), numa escola única, igual e para todos, conforme o dis- curso socialista dos dirigentes de Moçambique. Entretanto, a que resultados chegou a educação moçambicana orientada pela noção da politecnia, conforme o propósito transformador e igualitário defendido pelos dirigentes? Quais foram as contribuições da educação moçambicana, norteada pelo conceito de politecnia, para uma concepção socialista de educação?

Para se compreenderem os resultados alcançados pela educação moçambicana orientada pelo conceito de politecnia, conforme a proposta transformadora e igualitária dos dirigentes e as contribuições dessa educação para uma concepção socialista de educação, primeiro é focalizado o aparecimento do conceito de politecnia na história da Educação, as interpretações havidas sobre este em Marx e Lênin, e os rumos que a politecnia tomou no socialismo real.

\section{A emergência da politecnia na história da Educação}

0 conceito de politecnia, na história da Educação, surgiu das mudanças científicas ocorridas nos meados do século XIX, em função dos impactos que essas mudanças provocaram no processo de produção, marcando a passagem do artesanato à grande indústria. A transformação do processo produtivo, que decorreu das mudanças científicas havidas e o aparecimento da maquinaria, levou a que a realização do trabalho não mais dependesse do conhecimento específico que o trabalhador possuía sobre esse conhecimento. A automação do processo de produção, por meio da incorporação das funções manuais à máquina, simplificou o trabalho humano. Este passou a ser organizado de acordo com os "princípios científicos, simples e gerais” (Saviani, 2000, p. 163). Conforme Dore Soares (2000), o trabalho perdeu o seu caráter de especialização, tornou-se acessível a qualquer pessoa e, para a sua realização, era exigido ao trabalhador "a aquisição de habilidades e conhecimentos gerais e técnicos” (p. 337) ${ }^{13}$.

13. Marx inspirou-se no método educativo desenvolvido por Robert Owen (Dore Soares, 2003) 
De modo a inserir-se adequadamente no novo contexto técnico, científico e econômico, o trabalhador deveria dominar os novos códigos científicos, o que implicou "a disseminação dos códigos formais da escrita” (Saviani, 2000, p. 156). Assim, era necessário que o trabalhador tivesse outra qualificação profissional diferente da que ele até então possuía, que apenas respondia ao modo de produção artesanal. Essa nova qualificação somente poderia ser oferecida na escola e não na fábrica, como até então acontecia.

A escola popular da época, entretanto, que se restringia ao ensino de leitura, escrita e princípios de religião, não estava preparada para treinar profissionalmente os trabalhadores para a grande indústria. Assim, foi da busca de soluções educacionais para o problema decorrente de mudanças tecnológicas e os impactos que elas provocaram sobre a modalidade de aprendizagem artesanal que emergiu um novo método de educativo, a partir da experiência dos filantropos ingleses, entre os quais Robert Owen (Dore Soares; 1996; 2000; 2003).

0 novo método era baseado no ensino teórico - "os princípios gerais e científicos de todo o processo de produção" (Marx; Engels, 2004, p. 68) - unido ao prático - iniciar as crianças e os adolescentes no manejo de ferramentas elementares dos diversos ramos industriais (Marx; Engels, 2004).

A novidade apresentada pelo novo método em relação ao ensino artesanal foi a inclusão do trabalho na educação escolar, como princípio educativo, constituindo-se num avanço para a formação dos trabalhadores em face do tipo de preparação até então existente. Com esse novo método de ensino, os ofícios deixaram de ser um mistério acessível apenas ao mestre (Dore Soares, 1996). Eles foram universalizados por meio da qualificação profissional desespecializada, possibilitando que o trabalhador se adaptasse à diversidade dos trabalhos. A universalização dos ofícios, com a emergência da polivalência, criou a possibilidade de os trabalhadores mudarem de profissão com maior agilidade, graças ao método de ensino que, em lugar de ensinar apenas um ofí- cio, iniciava os trabalhadores no manejo de vários instrumentos de produção.

É nesse contexto que emergiu o conceito de politecnia na educação escolar, guardando, primeiramente, o significado de aprendizagem de várias técnicas: a polivalência.

Marx, inicialmente, criticou o método de ensino baseado na politecnia, afirmando que ele constituía um empreendimento burguês que apenas visava adestrar os "trabalhadores no maior número possíveis de ramos da atividade industrial" (Dore Soares, 1996, p. 148).

Com efeito, quando da simplificação do processo do trabalho e a conseqüente formação desespecializada, Marx (Marx; Engels, 2004) afirmou que o verdadeiro significado dessa formação

[...] para os economistas e filantropos, é a formação de cada operário [...] de tal modo que, se despedido de um trabalho pelo emprego de uma máquina nova, ou por uma mudança na divisão do trabalho, possa encontrar uma colocação o mais facilmente possível. (p. 91)

Em que pese essa crítica, Marx, entretanto, tinha uma análise dialética da realidade e percebeu que, se aquele método educativo tinha aspectos negativos, também "oferecia importantes elementos para a formação dos trabalhadores" (Dore Soares, 2000, p. 341). Marx sustentou que era necessário reconhecer a importância da variação dos trabalhos decorrente da desarticulação dos ofícios, no âmbito das transformações ocorridas na base científica da produção, por se tratar, segundo ele, de uma "questão de vida ou de morte" para os trabalhadores (Marx; Engels, 2004, p. 77).

Para Marx (Marx; Engels, 2004), a formação politécnica, no sentido que ele a definiu, junto com a educação intelectual e física, poderia

[...] substituir a monstruosidade de uma população operária miserável, disponível, mantida em reserva para as necessidades 
flutuantes da exploração capitalista, pela disponibilidade absoluta para a variedade de trabalhos. (p. 77-78)

Essa concepção educacional que também inclui a formação politécnica, além de substituir, segundo Marx (Marx; Engels, 2004), “o indivíduo parcial, mero fragmento humano que repete sempre uma operação parcial, pelo indivíduo integralmente desenvolvido para as qual as diferentes funções sociais não passariam de formas diferentes e sucessivas de suas atividades" (p. 78), também preservaria as crianças e os adolescentes da "ignorância, brutalização e degradação física e espiritual” (Marx; Engels, 2004, p. 75) de que eram vítimas na fábrica.

Por isso, a formação politécnica, fundada no princípio do trabalho, sem desprezar a formação intelectual de carácter geral, e a educação física, no entendimento de Marx (Marx; Engels, 2004), tendo rompido com a unilateralidade da escola artesanal, da popular e tradicional (a humanista), continha em germe a educação para o futuro.

Com essa análise dialéctica, Marx (Marx; Engels, 2004) aponta para a necessidade do fim da divisão técnica do trabalho, das desigualdades sociais e das desigualdades educacionais. Com efeito, para Marx, a divisão técnica do trabalho mutila as capacidades humanas e distingue os indivíduos em função dos tipos de atividades por eles realizados. A divisão técnica do trabalho faz com que aos indivíduos distintos caiba-lhes, respectivamente, "a actividade intelectual e a material; o gozo e o trabalho; o consumo e a produção" (p. 24). 0 fim da divisão técnica do trabalho, para Marx, também "significará a "emancipação de todos os sentidos e qualidades humanas (p. 42). A educação escolar, por sua vez, não pode ser a promotora das desigualdades socioeducacionais e da divisão técnica do trabalho.

A educação escolar, portanto, na sociedade socialista, não deve ser organizada em função da divisão técnica do trabalho, em que a ciência e os instrumentos do pensar são pro- priedade de alguns, destinando às maiorias as escolas técnicas estritamente profissionalizantes para atender às demandas do setor produtivo. Por isso, refere Marx (Marx; Engels, 2004), quando for conquistado

[...] o poder político pela classe trabalhadora, terá a adopção do ensino tecnológico, teórico e prático nas escolas dos trabalhadores. (p. 78)

Os trabalhadores, entretanto, conquistaram o poder político, por meio da Revolução, num país, à época, o mais pobre da Europa e com características feudais: a Rússia. Os dirigentes russos começaram a afrontar o problema de consolidar a tomada do poder e desenvolver o país mediante a industrialização, num contexto de grandes adversidades, entre as quais a 1 Guerra Mundial (1914-1918) e a demora da Revolução proletária em outros países da Europa, como esperava o movimento operário (Dore Soares, 2000; Losurdo, 2005).

No entanto, antes mesmo da Revolução russa, Lênin, o dirigente dessa Revolução, juntamente com Krupskaia, havia retomado as reflexões de Marx sobre a educação. Lênin buscava conceber uma escola que preparasse os trabalhadores para os desafios da conquista do poder político e construir o socialismo. Para isso, propuseram

[...] a instrução politécnica juntamente com a formação geral de base humanista, em substituição da ideia de ensino geral e profissional. (Dore Soares, 2000, p. 345)

A educação politécnica se inseria, portanto, num contexto de ruptura com as reminiscências de uma educação de tipo artesanal, baseada nas particularidades da profissão. A grande indústria trazia a universalização dos ofícios e é para esse aspecto que Krupskaia chama a atenção quando defende que a educação politécnica, promovendo uma formação técnica com características universais, visava proporcionar aos trabalhadores uma qualificação profissional segundo as exigências técnicas 
e científicas da produção. A esse respeito, Krupskaia (apud Dore Soares, 2000) observou que a instrução politécnica contribuía para a formação de jovens

\section{[...] bons trabalhadores para a diversidade} de trabalhos, conscientes da conexão lógica desse trabalho, ligando-o de modo bastante estreito à aquisição de conceitos e de competência. (p. 367)

Na proposição de Krupskaia, contudo, a instrução politécnica não estava destituída da formação geral. Essa última, de base humanista, visava formar jovens com competência política para serem dirigentes da sociedade. Assim, por meio da formação politécnica, complementada com a geral, seria possível consolidar a revolução socialista e industrializar o país.

A proposta educacional de Lênin e Krupskaia, no entanto, atravessou muitos percalços no seio do movimento operário. Conforme Jonhston (1989), Shulgin, por exemplo, admitiu que seria necessário preparar os trabalhadores para o mundo produtivo e que a melhor estratégia para isso seria a educação realizada na própria fábrica. Essa proposição resultou na defesa, por parte de Shulgin "da extinção da escola" (Jonhston, 1989, p. 155). Para Blonsky (apud Dore Soares, 2000), na fábrica, "os trabalhadores estariam livres da intromissão da cultura burguesa, ministrada através do ensino geral-humanista, e ganhariam a cultura proletária” (p. 355). Com Stalin, que assumiu a direção do movimento operário russo após a morte de Lênin, predominou a tendência profissionalizante na educação escolar russa, em função das exigências desenvolvimentistas (Dore Soares, 2000; Jonhston, 1989).

Desse modo, no seio do movimento operário russo, a instrução politécnica foi reduzida à simples preparação para o trabalho, segundo a exigência da industrialização do país. Ademais, o próprio conceito de politecnia perdeu o seu significado originário, isto é, a desespecialização ou polivalência, passando a ser entendido como profissionalização, justificando que essa profissionalização se faz sobre a base da união entre a teoria e a prática, entre o trabalho manual e intelectual.

A despeito dos impasses que a proposta educativa de Lênin e Krupskaia teve dentro do movimento operário russo, nela está latente o que há de fundamental do princípio de politecnia: a necessidade de formação de homens e mulheres conscientes do trabalho que desenvolvem no processo de transformação social, sintetizando o que eles compreenderam como unidade entre teoria e prática.

As reflexões de Marx em torno do conceito de trabalho como atividade do homem de transformação da natureza e de si mesmo são elucidativas para fundamentar a afirmação segundo a qual o processo educativo fundado na união entre a teoria e a prática, sob a base do trabalho, tem um alcance político, cultural e social e não apenas profissionalizante.

Com efeito, quando os trabalhadores enfrentavam os desafios concretos da Revolução Industrial - miséria generalizada, condições degradantes da fábrica, o ambíguo sistema de contratação de menores -, Marx defendeu o sentido profissionalizante da incorporação do trabalho na escola. Para este, tratava-se de preservar as crianças das condições fabris em que trabalhavam, "sem aprender qualquer trabalho que os torne úteis mais tarde" (Marx; Engels, 2004, p. 74), porque quando estas fossem consideradas velhas para o trabalho que exerciam, afirma Marx, "seriam despedidas da tipografia, indo aumentar as fileiras do crime" (Marx; Engels, 2004, p. 75).

No entanto, ao afirmar que o novo método educativo de união entre o trabalho e o ensino, proposto pelas escolas politécnicas e agronômicas ${ }^{14}$, contribuía para elevar a produção, Marx (1988), conforme escreve no Capital, via no conceito de produção uma dimensão

14. Por razões que ultrapassam este trabalho, não se vai proceder à discussão sobre o conceito de marxismo-leninismo, bem como as posições de várias correntes marxistas que vigoraram a partir do que os cientistas políticos denominam de segunda Internacional. Existe uma imensa bibliografia a respeito e o leitor poderá encontrar análises profundas na colectânea organizada por Hobsbawm (1982). 
política: era a produção da própria realidade social, por meio do trabalho humano, no sentido de atividade vital e transformadora.

É pelo trabalho, no sentido de atividade, que o homem transforma-se a si mesmo e a natureza. Assim, o trabalho é a práxis humana (Petrovic, 2002), constitui a mediação e a síntese da relação entre a teoria e a prática. Se for pela atividade humana que o homem transforma a si mesmo e a natureza na produção da realidade, seja social, política e econômica, para isso, é necessário que ele compreenda o processo que desenvolve e que seja consciente deste.

Em que pesem essas indicações do alcance político, social e cultural do princípio de ligação entre a teoria e a prática, à sua época, Marx não considerou a escola como importante frente de luta para a transformação social. Mesmo assim, ao refletir sobre o trabalho como atividade vital e transformadora e sobre o princípio de união entre a teoria e a prática no processo educativo, deixou importantes indicações para o movimento socialista na luta pela igualdade socioeducacional e pela transformação social, em que a escola constitui numa das principais frentes culturais dessa luta.

Posto isso, quando os dirigentes moçambicanos afirmaram a originalidade do princípio de ligação entre a teoria e a prática, entre a escola e o trabalho, num processo educativo que visava à formação do Homem Novo revolucionário, eles teriam se demarcado do entendimento do vínculo entre o ensino e o trabalho havido no socialismo real e, assim, se aproximado da filosofia de Marx? Responder a essa pergunta implica a análise do entendimento dos conceitos teoria, prática e trabalho na educação moçambicana.

\section{A fundamentação do conceito de politecnia em Moçambique}

Para expressar a vinculação entre a teoria e a prática, entre a escola e o trabalho no processo educativo, os dirigentes e intelectuais moçambicanos, no âmbito da edificação de uma sociedade socialista, interpretaram o conceito de politecnia em várias acepções.
A teoria, para aqueles dirigentes e educadores, era a linha política do partido, qual seja, o marxismo-leninismo. Além da linha política do partido, a teoria que os dirigentes moçambicanos defendiam na educação escolar também foi tomada no sentido positivista: o conhecimento científico com o qual deveria ser combatida a superstição e o obscurantismo da educação tradicional, que tomou conta da ciência (CEA, s/d, p. 3).

No entanto, de que marxismo-leninismo a Frelimo falava, haja vista: primeiro, a complexidade da definição do marxismo-leninismo em função do campo socialista terem emergido várias tendências ideológicas, tais como "a ortodoxa, a revisionista e a sindicalista revolucionária" (Waldenberg, 1982, p. 224)? Cada uma delas interpretou diversamente os princípios do marxismo, principalmente em relação às táticas e estratégias para tomar o poder e consolidá-lo. Segundo, o termo marxismo-leninismo é vago, pois ele não pode ser tomado como expressão da homogeneidade entre o pensamento de Marx e o de Lênin (Gruppi, 1996)? ${ }^{15}$

Em relação ao marxismo-leninismo moçambicano, cabe referir que os dirigentes da Frente afirmaram que ele proveio da própria experiência de luta, e definiram-no como "síntese teórica das ricas experiências das classes e povos oprimidos de todo o mundo, na sua luta secular contra os exploradores, pela instauração de um novo poder" (Frelimo, 1977a, p. 92). Então, a Frelimo, transformada em partido político de vanguarda, deveria guiar-se "pela síntese da experiência da luta revolucionária do povo moçambicano" (Frelimo, 1983a, p. 6). Entretanto, a síntese da experiência, por sua vez, era a própria Frelimo, uma vez que esta definiu a si mesma e a luta por ela dirigida como

[...] culminar de um processo de resistências seculares do povo moçambicano, conduzidas isolada e localmente contra o colonialismo de quinhentos anos. (Mazula, 1995, p. 103)

15. Relatório do Comitê Central ao III Congresso (Frelimo, 1977a). 
Além dessa explicitação, a Frente também definiu o marxismo-leninismo como "ideologia científica da classe trabalhadora" (Frelimo, 1977a, p. 47), de cujas aspirações ela era portadora (Frelimo, 1983b).

A adoção do marxismo-leninismo e a representação das aspirações da classe trabalhadora são apresentadas pela Frente como resultado de um processo natural. Documentos da Frelimo destacam que os seus membros, reunidos na V sessão do seu Comitê Central (1972), perceberam que havia uma similaridade entre os princípios que a Frente defendia e os do marxismo-leninismo (Frelimo, 1977a) ${ }^{16}$.

Nessa reunião, em face da "necessidade de aprofundar o conteúdo de classe e ideológico da luta", os intelectuais da Frente identificaram a Frelimo "com os interesses das classes trabalhadoras, e a linha política da Frelimo com a ideologia científica dos trabalhadores" (Frelimo, 1977a, p. 46-47). Por isso, a Frelimo deveria guiar-se "pela síntese das experiências da luta revolucionária do povo moçambicano" (Frelimo, 1983a, p. 6) e pela ideologia científica das classes trabalhadoras: o marxismo-leninismo.

Em que pese essa tentativa dos dirigentes da Frente explicarem a originalidade do seu marxismo-leninismo, alguns analistas políticos de Moçambique referem que a Frelimo era "indefinida e ambígua em relação ao marxismo" (Brito, 1995, p. 10), e que ela fora influenciada pelas tendências marxistas maoísta e a stalinista soviética que preponderava no Leste-Europeu (Brito, 1995; Nunes, 2000), além do marxismo iconoclasta do canadense John Saul (Fauvet; Mosse, 2003) ${ }^{17}$.

A influência maoísta sobre as idéias de alguns dirigentes, como Samora Machel, segundo Martins (2001), decorreu da convivência de Machel com os instrutores chineses que, durante a luta de libertação, "estiveram na base de guerra da Frelimo em Nachingweia” (p. 313) ${ }^{18}$. Seguindo sugestão daqueles instrutores, Machel "leu a quase totalidade das obras completas de Mao Tsé-Tung” (p. 313).

A versão stalinista do marxismo da Frelimo, conforme Brito (1995), proveio não apenas da cooperação internacional entre Moçambique e os países do eixo socialista, mas também dos jovens estudantes da ex-Universidade de Lourenço Marques, filhos da burguesia colonial que simpatizavam com o discurso marxista da Frente ${ }^{19}$. Segundo Brito (1995), eram jovens que detinham as competências técnicas, fundamentais ao funcionamento das instituições estatais nas mãos da Frelimo, e também eram eles "que manejavam com mais facilidade o discurso marxista” (p. 9).

Entretanto, é na aceitação de várias tendências teóricas, mas sem tomar uma posição em relação a nenhuma dessas tendências, que consiste, de acordo com Brito (1995), a indefinição e ambigüidade da Frelimo em relação ao marxismo. No entanto, os dirigentes moçambicanos admitiam a coexistência de diversas tendências marxistas, porque aqueles dirigentes estavam interessados na

[...] dimensão modernizadora, comum às diferentes correntes do marxismo que se confrontavam de forma mais ou menos latente na cena política moçambicana. Sendo prioridade a criação da nação, não havia desse ponto de vista nenhuma razão para se fazer uma opção em favor de um único modelo. (p. 14)

Foi a partir de uma visão modernizadora eclética e ajudados pelos cooperantes do LesteEuropeu que os dirigentes moçambicanos elaboraram o Plano Prospectivo Indicativo (PPI), o qual preconizava a eliminação do subdesenvolvimento do país em 10 anos (1980-1990) ${ }^{20}$.

Desse modo, a teoria defendida pelos dirigentes moçambicanos na educação escolar

16. John Saul foi professor de marxismo-leninismo na Universidade Eduardo Mondlane em Maputo.

17. Médico moçambicano, de ascendência portuguesa, foi o ministro da saúde na pós-independência. Participou, segundo a sua autobiografia, da Luta Armada de Libertação. Nachingweia foi a base militar da Frente situada na República da Tanzânia.

18. Atual Universidade Eduardo Mondlane em Maputo

19. 0 PPI, segundo Mazula (1995), nunca foi executado.

20. 0 discurso proferido em $1^{\circ}$ de Maio de 1976, durante o qual Samora Machel procedeu à mudança de nome da única instituição de Ensino Superior que havia em Moçambique. De Universidade de Lourenço Marques, a instituição passou a chamar-se Universidade Eduardo Mondlande em homenagem ao primeiro presidente da Frelimo. 
era constituída por dois elementos: a linha política do partido e o conhecimento científico. Ela precisava, para formar o Homem Novo, da prática, que era o trabalho no sentido de produção (Mazula, 1995). Nesse sentido, Machel (1976) chegou a afirmar que os trabalhadores dos países socialistas "edificam, com o seu trabalho e com sua consciência, a riqueza que permite elevar continuamente as condições de vida” (p. 3) ${ }^{21}$. Com aqueles trabalhadores "desenvolvendo a produção poderemos criar infra-estruturas que permitam o arranque da nossa economia”, uma vez que é o "trabalho que gera a riqueza" (Machel, 1976, p. 4).

Assim, na educação escolar, seria por meio do trabalho - no sentido de produção, isto é, trabalho na horta da escola - que o aluno estabeleceria o vínculo entre teoria e prática, segundo o objetivo das disciplinas de atividades manuais e laborais ${ }^{22}$. Essa vinculação entre a teoria e a prática, iniciada nas Zonas Libertadas, porém também estava fundamentada no positivismo: "a prática era o campo de verificação das teorias e fonte de todo o verdadeiro conhecimento" (Johnston, 1989, p. 155). É nesse sentido, referindo-se à experiência educacional das Zonas Libertadas, que Machel afirmou que, naquelas zonas,

[...] o estudo engloba as tarefas de produção, a teoria forja-se na prática e regressa na prática para se enriquecer com as experiências da sua aplicação concreta. Nestes centros, os estudantes demonstraram que a ciência nasce do trabalho e nele se desenvolve e só tem sentido quando a aplicamos no trabalho. (Frelimo, 1977d, p. 16)

Anos antes da independência do país, em face aos problemas que se verificaram no seio da Frente ${ }^{23}$, Machel (1974) lembrou aos militantes e militares da importância da prática como fonte do conhecimento:

[...] isto é mais importante quando o fenômeno em análise é uma experiência rica, cujo estudo e solução nos permitirão resolver situações idênticas que se verificarão inevitavelmente à escala nacional [...]. Fazendo-o, elevamos, pois as lições da prática à categoria de teoria, enriquecemos a nossa teoria revolucionária, instrumento indispensável da revolução. (p. 1-2)

Dirigindo-se aos professores, estudantes e funcionários da Universidade Eduardo Mondlane, Machel (1976) lembrou-lhes que todo conhecimento teórico, por mais que esteja na Universidade, também resultou da prática.

Com esses exemplos, pretende-se elucidar o uso variado dos conceitos teoria, prática e trabalho na educação moçambicana, os quais também receberam uma forte influência do maoísmo. Com efeito, é de Mao Tsé-Tung (1985) a afirmação segundo a qual "o conhecimento começa pela prática, atinge o conhecimento teórico e volta à prática” (p. 88).

Assim, os problemas da relação entre teoria e prática no ideário socialista de Moçambique, dado o peso das diversas correntes teóricas que influenciaram a opção socialista ali tomada, tornam frágil a afirmação dos dirigentes moçambicanos sobre a originalidade do seu marxismo-leninismo e também dos princípios pedagógicos que norteavam a educação moçambicana na perspectiva da politecnia. Ademais, Luis Felipe assegurou que

[...] esse tema da educação politécnica, no sentido como os países socialistas a tinham nunca foi profundamente aprovado aqui, [...] é verdade que o aluno para aprender tinha que aliar a teoria e a prática. Para nós, não era pela razão da politecnia, que a gente nem sabia bem o que era, quer dizer, nunca abordamos com propriedade o conceito da

21. Vide Manual de Atividades laborais (INDE, 1985).

22. Samora Machel aponta entre os problemas, o espírito de deixa andar, de vitória fácil, ou seja, havia, no seu entender, certo relaxamento no seio dos militantes e militares da Frente.

23. Luis Felipe, ex-chefe do Gabinete do Sistema de Educação no exMinistério de Educação e Cultura de Moçambique. Entrevista concedida ao autor da pesquisa, em Maputo, em 15 de Janeiro de 2005. 
politecnia, nós do Ministério da Educação nunca abordamos esse tema [...]. ${ }^{24}$

Se uma parte dos técnicos moçambicanos não tinha clareza do significado de educação politécnica, prossegue Luiz Felipe, o mesmo se verificou em relação à pedagogia socialista:

[...] é verdade, mas o problema que se fala é o seguinte: nós nunca acreditamos que houvesse uma pedagogia socialista, primeira coisa: [...] esse conceito são alguns professores dos paises socialistas que traziam, diziam da pedagogia socialista [...].

Sendo assim, a que pedagogia socialista se referiam os organizadores do SNE? Por que a pedagogia socialista, referida nos princípios universais do marxismo-leninismo, é afirmada, nas Linhas Gerais do Sistema Nacional de Educação e na Lei 4/83 de 23 de Março, como um dos fundamentos desse Sistema Educacional? Teria sido uma expressão imposta pelos técnicos do LesteEuropeu, em função da condicionalidade da cooperação (Plank, 1993), sem que os intelectuais moçambicanos soubessem do que se tratava?

São interrogações que ficaram sem resposta.

\section{Limites da educação socialista moçambicana}

Contrariamente ao entendimento marxiano e leniniano do conceito de politecnia no sentido de desespecialização, os dirigentes e educadores moçambicanos defenderam que a politecnia era a base da formação do Homem Novo, mas numa perspectiva de especialização. Na concepção dos dirigentes de Moçambique, o ensino colonial foi deficiente em relação ao aluno porque "não o preparava para desenvolver uma atividade especializada num setor de trabalho, mas para fazê-lo brilhar nos salões luxuosos da burguesia, exibindo aquilo a que pomposamente se chamava sólida cultura" (Frelimo, 1977d, p. 7). Por isso, a Frente defendeu a especialização como norte da nova educação orientada pelo conceito de politecnia.
Os dirigentes e intelectuais moçambicanos, provavelmente, não teriam discutido com afinco o conceito de politecnia porque lhes interessava a rápida industrialização do país, segundo o PPI. Assim, deram grande importância ao ensino técnico-profissional, tendo sido criada uma secretaria de estado específica para esse nível ensino (Diploma ministerial 56/86).

A educação politécnica, de acordo com a Lei 4/83 de 23 de março de 1983, deveria ser oferecida no ensino geral. Todavia, o princípio pedagógico de ligação entre a teoria e a prática, entre a escola e o trabalho, também deveria ser a base de formação no ensino técnico profissional. Por quê?

A necessária ligação entre a teoria e a prática, entre a escola e o trabalho, no processo educativo moçambicano, tinha um alcance político-partidário. Essa ligação foi uma fórmula política adotada pelos dirigentes moçambicanos para fazerem com que as maiorias sociais "aderissem, inquestionavelmente, às orientações da Frente, ao sistema político e à classe no poder" (Lopes, 1995, p. 163).

Entendendo a teoria como linha política do partido, ninguém deveria questioná-la. Quem o fizesse, defende Machel, "deve-se combater energicamente” (Frelimo, 1974, p. 11). Assim, os alunos deveriam mostrar na prática (realidade empírica) e na práxis (ação) que estão de acordo com linha política e as orientações da Frente, porque "o ídolo na escola é a nossa linha política [...], o forte é a nossa orientação que o Ministério da Educação dá. 0 resto é trapos" (Machel, 1978, VI). Então, questionar as orientações da Frelimo era o sinônimo de ser "reaccionário, o inimigo do Povo" (Colaço, 2001, p. 97), propenso a ser enviado para os campos de reeducação onde, por meio do trabalho, deveria adquirir novas idéias para se integrar à nova sociedade (Ncomo, 2005). Assim, mediante a educação política, os alunos deveriam ter o amor pela Frelimo e pelos seus

24. Não foi possível auferir, no Ministério dos Negócios Estrangeiros e da Educação, dados quantitativos dos moçambicanos que foram para esses países 
dirigentes (MEC, 1979).

Dado que a Frelimo afirmou que era representante da classe trabalhadora, a ligação entre o estudo e o trabalho no processo educativo também visava formar nos alunos a mentalidade de trabalhadores. Assim, por meio da prática, que compreendia o trabalho no sentido de produzir no campo da escola, pretendia-se levar o "estudante a desenvolver o gosto e o amor pelo trabalho e os trabalhadores" (Mined, 1988/9, p. 57).

A ligação da escola com o trabalho produtivo também deveria ser efetivada, levando o aluno a uma unidade de produção (fábrica), quer durante o período letivo, quer durante as férias. Com isso, completava-se a educação para o amor ao trabalho e ao trabalhador, pois alguns alunos, sendo individualistas e elitistas, desprezavam as massas trabalhadoras (Machel, 1977).

Com isso, a educação socialista moçambicana, orientada pelo conceito de politecnia, mostrou-se limitada quanto ao propósito transformador defendido pelos dirigentes em função do limitado entendimento e aplicação desse conceito na educação; da simples repetição do discurso maoísta e stalinista, sem de fato demarcarem o âmbito dessas tendências marxistas. 0 princípio de ligação entre a teoria e a prática e entre a escola e o trabalho serviu para afirmar a ditadura do partido.

\section{Contradições do discurso socialista}

Além de a educação moçambicana ter se mostrado limitada em relação ao propósito transformador, o discurso socialista que acompanhou essa educação foi contraditório. Os dirigentes moçambicanos defendiam, entre vários ideais socialistas, a igualdade socioeducacional, razão por que criticaram o elitismo do sistema de ensino colonial e propuseram o princípio de ligação entre a teoria e a prática no processo educativo, cuja tradução estaria no caráter politécnico da educação.

Não se pode afirmar que não houve realizações significativas em Moçambique no âmbito educacional em relação ao período colonial. Somente para exemplificar, deixou de haver dois sistemas educacionais em Moçambique e um maior número de moçambicanos teve acesso à educação escolar comparativamente ao período colonial (PNUD, 2000).

Os dirigentes de Moçambique também assinaram acordos de cooperação com países do bloco socialista, com destaque para Cuba e a exUnião das Repúblicas Socialistas Soviéticas (URSS), para onde foram enviados muitos moçambicanos ${ }^{25}$. Naqueles países, estes deram continuidade aos seus estudos secundários, técnico-profissionais e mesmo superiores.

Em que pesem essas realizações, o principio de ligação entre a teoria e a prática serviu de critério para a seleção educacional. Com efeito, os dirigentes defendiam "a igualdade de oportunidades que tem qualquer cidadão de acesso a todos os níveis de educação, com base na introdução da escolaridade obrigatória, gratuita, universal e laica” (MEC, 1980, p. 2). No entanto, em face da reivindicação popular pela educação, os dirigentes, sob justificativa de conter e controlar a explosão escolar, regulamentavam a limitação de acesso:

0 ministério da Educação, no quadro de uma planificação central, definirá o número de alunos que poderão anualmente ingressar nas escolas primárias, secundárias e superiores, bem como o número, localização e tipos de escolas que deverão ser abertas em cada ano. (Resolução 8/79 de 3 de julho de 1979, n. 2) 0 dispositivo legal ainda refere que no âmbito das tarefas revolucionárias, os grupos de vigilância deveriam zelar para que os alunos que terminassem a quarta série, mas sem poderem continuar com os estudos, 'não afluíssem aos centros urbanos'. (Resolução 8/79 de 3 de julho, n. 3)

Desse modo, os dirigentes do partido e do Estado, ao mesmo tempo em que defendiam a massificação da educação, impediam, nos

25. No Brasil, seriam as secretarias municipais de educação. 
moldes do colonizador, que as maiorias sociais afluíssem aos centros urbanos onde se localizavam as escolas com níveis de ensino além do primário. De modo a melhor controlarem o afluxo das maiorias do campo para a cidade, sub a justificativa da guerra civil (período de 1977 a 1992) e vigilância sobre os inimigos da revolução, foi instituída a guia de marcha: documento emitido pelos grupos dinamizadores da residência permanente do viajante, era condição para o deslocamento quer do campo para a cidade como no sentido inverso. Nela constavam os dados completos, os motivos da viagem, o prazo de estadia e a data de retorno.

Ainda em nível educacional, enquanto para as maiorias sociais era regulamentado o limite de acesso à educação em condições de igualdade, além das escolas do partido destinadas às elites dirigentes, o Ministério da Educação e Cultura defendeu, como critério para ingresso e continuação dos estudos em níveis mais elevados, segundo o princípio pedagógico de ligação entre a teoria e a prática, o grau de militância e engajamento na revolução (Diploma ministerial $n^{\circ}$ 14/81 de 18 de fevereiro de 1981).

0 dispositivo legal regulamentava o curso noturno que, em princípio, face ao grau de analfabetismo das maiorias sociais, deveria estar a serviço dessas maiorias, pois as médias de idade eram incompatíveis com as médias estabelecidas para o ingresso no curso diurno de ensino.

Assim, conforme aquele dispositivo legal, tinham prioridades de ingresso no curso noturno, segundo a ordem decrescente:

1. Membros de estruturas de direção do partido nos diversos escalões;

2. Forças de defesas e de segurança;

3. Sectores prioritários da economia nacional, especialmente as empresas sob controle do Conselho de ministros;

4. Outras empresas;

5. População em geral.

0 Ministério da Educação justificou essa seleção socioeducacional apoiado no princípio pedagógico de ligação entre a teoria e a prática, segundo entendido pelos dirigentes:

[...] comportamento sócio-político demonstrado; anos de interrupção de estudos por motivos de dedicação à causa da Reconstrução Nacional. (Diploma Ministerial 14/81, Capítulo 11, artigo 6, alíneas a e f)

Em relação ao nível superior, além da seleção feita pelas direções distritais de educação ${ }^{26}$, também deveria observar-se o critério de militância, ou seja, "a atitude permanente do militante em relação às massas” (Buendia Gómez, 1999, p. 250). Machel (apud Buendia Gómez, 1999) justificou o critério com base no princípio pedagógico de ligação entre a teoria e a prática. Para o dirigente moçambicano, era "justo que quem avançasse para níveis mais altos de formação tivesse dado provas que manteria a sua capacidade científica e cultural ao serviço dos trabalhadores" (p. 250). Assim, o acesso aos níveis mais elevados de escolarização constituía um prêmio pela militância política, seja mediante o cumprimento das normas do Partido, seja pela denúncia contra os inimigos do povo, e de acordo com o critério de classe (Mazula, 1995).

Com isso, ficam evidentes as contradições de um discurso socialista que defendeu a politecnia, como base para a constituição de uma escola única que rompesse com o dualismo da escola colonial. Um discurso socialista que afirmava a igualdade socioeducacional e o direito de os trabalhadores ascenderem aos mais altos níveis de escolarização. No entanto, o mesmo discurso, apoiado num entendimento sui generis do princípio de ligação entre teoria e prática, escola e trabalho, procedeu à seleção socioeducacional.

É no âmbito dessa seleção, justificada em função da necessidade da formação de força de

26. 0 acesso ao nível elementar era feito após a conclusão das cinco primeiras séries de escolarização; ao nível básico, após a conclusão do ciclo preparatório (sete anos); e ao nível médio, em caso do desejo de interrupção do primeiro ciclo do ensino secundário geral (10 anos de escolaridade) ou quando indicado pela direção da escola. 
trabalho qualificada para a efetivação do PPI (Mazula, 1995) e do professorado para as tarefas educacionais, que a escola socialista moçambicana foi (e ainda continua) dualista: de um lado, o ensino geral e, de outro, o técnico-profissional, desde o nível elementar até o médio.

Com esse dualismo, a educação socialista moçambicana promoveu a divisão técnica do trabalho, pois não ofereceu a todos os moçambicanos as mesmas oportunidades de adquirirem, na mesma escola, as bases técnico-científicas para transformarem a natureza e a sociedade, segundo defenderam os dirigentes e intelectuais moçambicanos quando propuseram a politecnia como base do processo de formação do Homem Novo.

Numa situação de privilégios, "os filhos das elites dirigentes e de certas elites bem conceituadas” (Mazula 1995, p. 139), a partir da influência e das intervenções dos pais no partido e no Estado, não eram afetos ao ensino técnico-profissional. Continuavam os seus estudos no ensino secundário geral que dava o acesso à universidade, "principalmente nos cursos de medicina, engenharia e direito" (Mazula, 1995, p. 139). Eram os filhos dos camponeses e dos operários que, em nome do cumprimento das tarefas revolucionárias e segundo o princípio de ligação entre a teoria e a prática, deveriam aceitar freqüentar o ensino técnico-profissional e os cursos de magistério.

Em nível de discurso socialista, os dirigentes ainda defendiam, como um dos princípios universais do marxismo-leninismo, que a "cada um segundo as suas capacidades, e cada um recebia segundo o seu trabalho" (Frelimo, 1977a, p. 74).

0 trabalho de cada um, feito segundo as suas capacidades, era remunerado por meio de salário. Na definição dos salários, os dirigentes argumentaram que se "deve aplicar o princípio de pagar mais a quem trabalha mais, a quem realiza melhor trabalho e a quem atinge maiores índices de eficiência e de produtividade" (Frelimo, 1983b, p. 66). Assim, para quem produzir menos ou com fraca qualidade, "temos que introduzir a prática de pagar menos" (Frelimo, 1983b, p. 67). Com essa práxis, argumentaram os dirigentes moçambicanos,

\section{[...] caminharemos seguramente para a materialização do princípio socialista de cada um segundo as suas capacidades e a cada um segundo o seu trabalho. (Frelimo, 1983b, p. 67)}

Se cada um teve acesso à escola diferente, como exigir a mesma capacidade e qualidade de produção? Eis a contradição de um discurso socialista.

\section{Consideraçōes finais}

Afirmou-se, na introdução do presente trabalho, que se pretendia fazer uma análise da fundamentação do conceito de politecnia presente no projeto socialista para a educação moçambicana, apresentado pela Frelimo, no âmbito da edificação do socialismo em Moçambique.

Da análise da fundamentação do conceito, inferiu-se que o entendimento deste foi limitado e que o discurso socialista que acompanhou essa educação foi contraditório. Não existe uma ordem de fatores que, por si só, pode explicar os limites dos objetivos emancipatórios e transformadores da educação moçambicana e da contradição do discurso socialista que acompanhou essa educação. A coexistência de diversas tendências marxistas e a não-compreensão do próprio marxismo, por uma boa parte da elite dirigente moçambicana, talvez ofereça uma chave compreensiva do processo político e socioeducacional moçambicano. Por mais que esses dirigentes buscassem afirmar a originalidade do seu marxismo e também dos princípios pedagógicos que orientavam a educação escolar moçambicana, essa originalidade não existiu.

Assim, a fundamentação do conceito de politecnia teria resultado da influência do marxismo positivista de Mao Tsé-Tung, presente em muitos discursos de Samora Machel. Ademais, a falta de profissionais da Educação altamente qualificados, logo após a independência, talvez 
esteja na origem da ausência de estudos sobre os fundamentos pedagógicos e filosóficos da educação moçambicana, tendo resultado na adopção de métodos e filosofias educacionais propostas pelos parceiros de cooperação, nesse caso, os especialistas do Leste-Europeu.

Em que pesem os limites da educação moçambicana orientada pelo princípio de politecnia e as contradições do discurso soci- alista que acompanhou essa educação, esperase, entretanto, que a atual retomada do conceito de politecnia, como filosofia educacional dos Institutos Superiores Politécnicos recentemente criados (2004), no âmbito da expansão do Ensino Superior público, seja acompanhada de estudos sobre o mesmo conceito e a sua pertinência na educação moçambicana, que ainda está em busca dos respectivos rumos.

\section{Referências bibliográficas}

BRITO, L. de Moçambique independente: o novo espaço político. Texto de apoio. Maputo: Universidade Eduardo Mondlane, UFICS, 1995, mimeo

BUENDIA GOMÉZ, M. Educação moçambicana: história de um processo. Maputo: Livraria Universitária, 1999.

CEA - Centro de Estudos Africanos: Universidade Eduardo Mondlane. Educação no Moçambique livre. Maputo: CEA, s/d, pasta ก. 96.7,6/E.

COLAÇO, J. C. Trabalho como política em Moçambique: do período colonial ao regime socialista. In: FRY, P. (Org.). Moçambique Rio de Janeiro: Ensaios, 2001, p. 91-110.

DORE SOARES, R. Escola Nova versus Escola Unitária: contribuições para o debate. Educação e Sociedade. Campinas: CEDES 1996, n. 54, jan. p. 141-150.

Gramsci: 0 Estado e a escola. ljuí: Unljuí, 2000.

Educação, reprodução e luta ideológica: Marx, Lenin, Gramsci e a escola. In: GUIMARÃES, A. et al. (Orgs.). Marxismo e ciências humanas. São Paulo: Xamã, 2003, p. 311-326.

FAUVET, P.; MOSSE, M. É proibido pôr as algemas nas palavras: Carlos Cardoso e a revolução moçambicana. Maputo: Ndjira, 2003.

FRELIMO. Relatório do Comitê Central ao $3^{\circ}$ Congresso. Maputo. Departamento do trabalho ideológico da Frelimo, 1977 a.

0 processo revolucionário da guerra popular de libertação. Maputo: Edição do Departamento do trabalho ideológico da Frelimo, 1977b.

Directivas econômicas e sociais do Terceiro Congresso da Frelimo. Maputo: Frelimo, 1977c.

Estudemos e façamos dos nossos conhecimentos um instrumento de libertação do povo. Maputo: Departamento do trabalho ideológico da Frelimo, 1977d. n. 8. (Coleção Palavras de ordem)

Estatutos e Programas do Partido Frelimo. Maputo: Instituto Nacional do Livro e do Disco (INLD), 1983a.

Relatório do Comitê Central ao Quarto Congresso da Frelimo. Maputo: Imprensa Nacional, 1983b.

GRUPPI, L. Tudo começou com Maquiavel: as concepções de Estado em Marx, Lenin e Gramsci. 14 ed. Porto Alegre: L\&PM, 1996.

HOBSBAWM, E. J. (Org.). História do marxismo: o marxismo na época da segunda Internacional. Tradução de Leandro Konder e Carlos Nelson Coutinho. Rio de Janeiro: Paz e Terra, 1982. 
JOHNSTON, A. Study, produce and combat: education and mozambican state - 1962-1984. Stockholm: Institute of International Education; University of Stockholm, 1989.

LOPES, J. de S. M. Formação de professores primários e identidade nacional em Moçambique. Dissertação (Mestrado). Faculdade de Educação, Universidade Federal de Minas Gerais, Belo Horizonte, 1995.

LOSURDO, D. Fuga da história? A revolução russa e a revolução chinesa vistas hoje. Rio de Janeiro: Revan, 2004.

MACHEL, S. Fazer da escola uma base para o povo tomar o poder. Frelimo, 1974. Caderno n. 6. (Coleção Estudos e orientações)

A classe trabalhadora deve conquistar e exercer o poder na frente da ciência e da cultura. Maputo: Universidade Eduardo Mondlane, 1976.

. Estudemos e façamos dos nossos conhecimentos um instrumento de libertação do povo. Maputo: Departamento do trabalho ideológico da Frelimo, 1977d, n. 8. (Coleção Palavras de ordem)

. A revolução é irreversível. Revista Tempo. Maputo, 1978a, n. 390, 26 de março. Caderno Especial, p. 31-37.

. Venha o inimigo de onde vier, nós o puniremos. Revista Tempo. Maputo. 1979a, n. 448, 13 de maio, p. 26-36.

MAO TSÉ-TUNG. Política. São Paulo: Ática, 1982.

MARX, K. 0 capital. São Paulo: Abril cultural, 1988, v. I.

MARX, K.; ENGELS, F. Textos sobre educação e ensino. São Paulo: Centauro, 2004.

MARTINS, H. Porque Sakrani? Memórias dum médico de uma guerrilha esquecida. Maputo: Terceiro Milênio, 2001.

MAZULA, B. Educação, ideologia e cultura em Moçambique: 1975-1985. Porto: Afrontamentos, 1995.

MEC. Ministério da Educação e Cultura. Programa de estudos políticos. Maputo: INLD, 1979.

Linhas gerais do Sistema Nacional de Educação. Maputo: 1980. Disponível no Centro de Estudos Africanos da Universidade Eduardo Mondlane, pasta 67.9, 6/LK.

Diploma ministerial n. 14/81 que regulamenta o ingresso nos cursos nocturnos. Boletim da República. Maputo, 18 de fevereiro de 1981, I série, n. 7.

Diploma ministerial 56/86 que estabelece os Estatutos da Secretaria de Estado do Ensino Técnicoprofissional. Boletim da República. 22 de outubro de 1986, p. 144.

MINED. Ministério da Educação. Orientações e tarefas escolares obrigatórias para os anos lectivos de 1988/89. Maputo: Imprensa Nacional, 1988/9.

MOÇAMBIQUE, República Popular. Constituição da República Popular de Moçambique (1975). Principal Legislação publicada na República Popular de Moçambique. Maputo: Ministério da Justiça, 1977.

Sistema Nacional de Educação. Linhas Gerais e Lei n. 4/83. Maputo: Minerva Central, 1985.

MUNSLOW, B. Mozambique: the revolution and its origins. London: Longman, 1983.

NCOMO, B. L. Uria Simango: um homem, uma causa. 2 ed. Maputo: Nova África, 2005.

NUNES, C. A armadilha: incorporação e exclusão na sociedade do trabalho. Rio de Janeiro: Educam; Clacso, 2000.

PETROVIC, G. "Práxis". In: BOTTOMORE, T. Dicionário do pensamento marxista. Rio de Janeiro: Jorge Zahar, 2001.

PLANK, D. N. Cooperação e condicionalidade. 0 Estado moçambicano na nova ordem mundial. Cadernos de Pesquisa. Maputo. Instituto Nacional do Desenvolvimento da Educação, n. 3, 1993. 
PNUD. Programa das Nações Unidas para o Desenvolvimento (PNUD). Educação e desenvolvimento humano: percurso, lições e desafios para o século XXI. Relatório Nacional do Desenvolvimento Humano. Maputo: PNUD, 2000.

SAVIANI, D. 0 trabalho como princípio educativo frente às novas tecnologias. In: FERRETTI, C. et al. (Orgs.). Novas tecnologias, trabalho e educação: um debate multidisciplinar. Petrópolis: Vozes, 2000, p. 151-168.

VIEIRA, S. 0 Homem Novo é um processo. Movimento das Ideias. CEA-UEM, 1977. Pasta 967.9, 6/H.

WALDENBERG, M. A estratégia política da social-democracia alemã. In: HOBSBAWM, E. J. (Org.). História do marxismo: 0 marxismo na época da segunda Internacional. Tradução de Leandro Konder e Carlos Nelson Coutinho. Rio de Janeiro: Paz e Terra, 1982.

Recebido em 01.06.06

Aprovado em 04.09.06

António Cipriano Parafino Gonçalves, doutorando em Educação na UFMG, professor de Filosofia da Linguagem e Filosofia da Educação na Universidade São Tomás de Moçambique (Maputo) e de Filosofia e Metodologia de Trabalho Científico na Universidade Técnica de Moçambique, pesquisa na área de Políticas Públicas e Educação, com interesses nas relações entre trabalho e educação, filosofia e educação e políticas de Ensino Superior. 